\title{
CrystEngComm
}

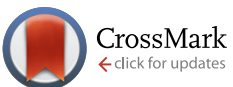

Cite this: CrystEngComm, 2015, 17, 6878

Received 30th March 2015,

Accepted 10th July 2015

DOI: $10.1039 / \mathrm{c} 5 \mathrm{ce} 00629 \mathrm{e}$

www.rsc.org/crystengcomm

\section{Aluminum zinc oxide nanostructures with customized size and shape by non-aqueous synthesis $\dagger$}

\author{
S. Zellmer, A. Kockmann, \$. Dosch, B. Temel and G. Garnweitner*
}

\begin{abstract}
The non-aqueous sol-gel synthesis of aluminum zinc oxide (AZO) nanocrystals with controllable size and morphology at comparatively low temperatures is presented. By varying the reaction chemistry, customized aluminum zinc oxide nanorods and nanospheres with adjustable composition and tailored morphology between $\mathrm{OD}$ and $1 \mathrm{D}$ were obtained. We furthermore show that the bandgap can be engineered by the Al content. Additionally, the growth kinetics and the influence of various process parameters such as the reaction temperature and precursor concentration as well as the scale-up from a $45 \mathrm{~mL}$ autoclave to a $500 \mathrm{~mL}$ reactor were investigated.
\end{abstract}

\section{Introduction}

Aluminum zinc oxide (AZO) as a transparent conductive material is considered a cheap alternative to indium tin oxide (ITO) due to its similar optical and electrical properties. ${ }^{1-6}$ Besides its high transparency in the visible region, the n-type semiconductor aluminum zinc oxide offers low resistivity and good stability for use in thin-film solar cells, touch panels, displays or light-emitting diodes. ${ }^{7-12}$ The use of preformed nanoparticles of transparent conductive oxides (TCOs) is becoming an increasingly attractive alternative to thin film deposition techniques, offering great benefits for printable electronics. This necessitates the availability of high-quality nanocrystals with customized particle size and shape as well as a defined doping level for controlled properties and optimum performance. ${ }^{13,14}$

Generally, liquid phase-based processes have shown to be advantageous for the synthesis of metal oxides with high purities at moderate temperatures. Recently, different hydrothermal processes have been discussed in the literature for the synthesis of AZO nanostructures with high crystallinity at low reaction temperatures. ${ }^{15,16}$ However, the obtained products usually are composed of nanoparticles with a broad size distribution and variations in morphology. Another promising

Institute for Particle Technology and Laboratory for Emerging Nanometrology, Technische Universität Braunschweig, Volkmaroder Str. 5, 38104 Braunschweig, Germany.E-mail: g.garnweitner@tu-braunschweig.de

$\dagger$ Electronic supplementary information (ESI) available: Aspect ratios of the AZO nanocrystals synthesized in the $500 \mathrm{~mL}$ reactor system and for different $\mathrm{Al}$ doping levels; thermogravimetric analysis of the AZO nanocrystals; optical bandgap of the AZO nanoparticles and nanorods; further XRD patterns and TEM images. See DOI: 10.1039/c5ce00629e

$\$$ The authors contributed equally to this study. strategy is the non-aqueous or solvothermal synthesis which has been proven capable of synthesizing a variety of metal oxides, resulting in high crystallinity, adjustable doping levels and narrow particle size distributions. ${ }^{17,18}$ In contrast to the typical sol-gel synthesis, aromatic organic solvents such as benzyl alcohol, amines or ketones were used to realize moderate reaction rates during the synthesis, resulting in more homogeneous products with defined morphologies. ${ }^{18,19}$

The first investigations to synthesize Al-doped $\mathrm{ZnO}$ nanostructures using the non-aqueous synthesis were carried out using microwave-assisted procedures, wherein essentially roundish nanoparticles were obtained and utilized to prepare transparent conducting films..$^{13,20,21}$

In this contribution, we show that the synthesis of AZO nanocrystals can be successfully accomplished also by conventional heating in a reactor. By careful adjustment of the reaction chemistry, the morphology of the nanocrystals can be tuned between $0 \mathrm{D}$ and $1 \mathrm{D}$, which is shown to be due to the different functional groups of the used solvents. Combining precise control of the reaction chemistry with knowledge about the influence of other reaction parameters allowed us to produce AZO nanocrystals with both tailored size and morphology as well as tailored composition and thus adjustable electronic and optical properties.

\section{Experimental}

\subsection{Synthesis of AZO nanocrystals}

Zinc acetylacetonate hydrate (powder, Aldrich), aluminum acetylacetonate ( $\mathrm{Al}(\mathrm{acac})_{3}, 99 \%$, Aldrich) and aluminum isopropoxide $\left(\mathrm{Al}(\mathrm{OiPr})_{3}, \geq 98 \%\right.$, Aldrich) were used as precursors for the preparation of AZO nanoparticles. The concentrations of the precursors were in the range of 6.35 up to $152.36 \mathrm{~g} \mathrm{~L}^{-1}$, 
whilst the content of the aluminum precursor was varied between 1.0 and $30 \mathrm{~mol} \%$, as described below. As reaction media, the pure solvents benzyl alcohol $(\mathrm{BnOH}, \geq 99.9 \%$, Fluka) and benzylamine $\left(\mathrm{BnNH}_{2}, \geq 99.0 \%\right.$, Fluka) as well as mixtures of benzyl alcohol and benzylamine (25, 50 and 75 vol\% $\mathrm{BnNH}_{2}$ in $\mathrm{BnOH}$ ) were utilized. For the nanocrystal synthesis at different scales, steel autoclaves equipped with Teflon liners $(45 \mathrm{~mL})$ and alternatively a $500 \mathrm{~mL}$ steel reactor furnished with an additional glass liner (Parr instruments) were used to achieve reaction temperatures of 80 to $200{ }^{\circ} \mathrm{C}$ and reaction times between $30 \mathrm{~min}$ and $96 \mathrm{~h}$. Unless stated otherwise, a precursor concentration of $50.8 \mathrm{~g} \mathrm{~L}^{-1}$ (with 2.5 $\mathrm{mol} \% \mathrm{Al}$ ) was utilized with a reaction temperature of $200{ }^{\circ} \mathrm{C}$ and a reaction time of $24 \mathrm{~h}$. After the synthesis, the particles were separated from the reaction medium using centrifugation (10 $\mathrm{min}$ at $7500 \mathrm{rpm}$ ), washed twice with chloroform and dried at room temperature under vacuum for 1 day.

\subsection{Characterization}

Powder X-ray diffraction (PXRD) $\left(\mathrm{CuK}_{\alpha}\right.$ radiation; Empyrean $\mathrm{Cu}$ LEF HR goniometer; Empyrean series 2, PANalytical, PIXcel-3D detector; Si wafer; $20-90^{\circ}$, step size $0.05^{\circ}$ ) was utilized to determine the phase and crystallinity. ICP-OES (Varian 715-ES) was performed for the determination of the Al content in the synthesized nanoparticles. TEM images of the different samples were taken with a LEO 922 A (Carl Zeiss) as well as a Tecnai G2 F20 TMP (FEI) at $200 \mathrm{kV}$. UV-Vis measurements were carried out using a UV-3100PC spectrophotometer by VWR; concentrations of $10 \mathrm{~g} \mathrm{~L}^{-1}$ were used and measured in an optical range of 600 to $220 \mathrm{~nm}$. The amount of bound organics at the particle surface was measured using thermogravimetric analysis (Mettler Toledo TGA/DSC) under oxygen flow in the range of $25-800^{\circ} \mathrm{C}$ at $10^{\circ} \mathrm{C} \mathrm{min}^{-1}$.

\section{Results and discussion}

\subsection{Influence of the reaction chemistry}

Typically, $\mathrm{ZnO}$ occurs in the hexagonal wurtzite structure with lattice parameters of $a=3.2499$ and $c=5.2066 \AA^{22,23}$ The synthesized AZO nanoparticles maintained as well the wurtzite structure of $\mathrm{ZnO}$. Based on different aspects, such as the surface energy and various material properties, anisotropic crystal growth along the $c$-axis can be observed ${ }^{22,24}$ and is commonly found for the water-based synthesis of $\mathrm{ZnO}$ nanoparticles. ${ }^{25}$ Fig. 1 shows the PXRD patterns of the AZO nanoparticles obtained in benzyl alcohol and in benzylamine using precursor concentrations of $50.8 \mathrm{~g} \mathrm{~L}^{-1}$ and $25.4 \mathrm{~g} \mathrm{~L}^{-1}$, respectively, in comparison to the reference pattern for $\mathrm{ZnO}$ (ICSD database, no. 98-016-5010). In both cases, highly crystalline products with all reflections matching the wurtzite phase are found. The samples consist of nanosized crystallites as recognized by the signal broadening, with sizes calculated by the Scherrer equation to be about $12 \mathrm{~nm}$ (benzyl alcohol sample) and $25 \mathrm{~nm}$ (benzylamine sample) from the (010) reflection. Particularly the (002) reflection however appears significantly sharper for the benzyl alcohol sample,

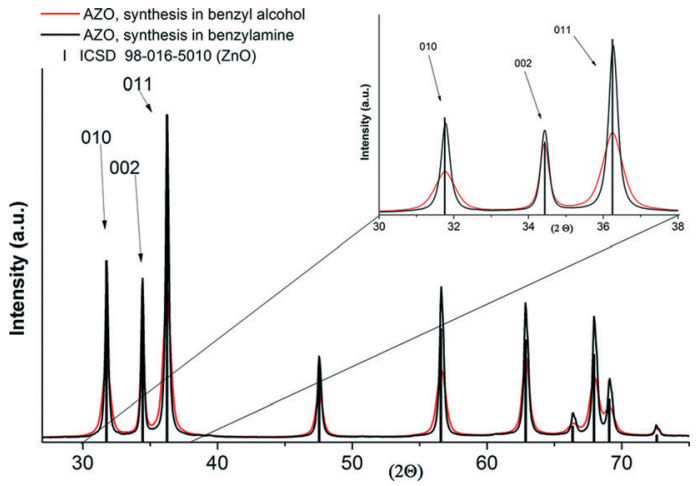

Fig. 1 PXRD pattern of the obtained AZO nanoparticles compared to the $\mathrm{ZnO}$ reference (ICSD database, no. 98-016-5010).

and the crystal size was calculated to be about $40 \mathrm{~nm}$ from this reflection, indicating the formation of rod-shaped AZO nanoparticles with preferred growth in the crystallographic $l$ direction. For the benzylamine sample, comparable broadening of all the reflections suggests similar dimensions in all crystal directions. The TEM images of the products obtained from the two systems are shown in Fig. 2, clearly evidencing the different morphologies. Furthermore, the diameter and length of the AZO nanorods were determined on average to be about 12 and $45 \mathrm{~nm}$, respectively; hence, the particles are single crystalline and the crystallite size can be equalized with the primary particle size. In comparison to the synthesis in $45 \mathrm{~mL}$ steel autoclaves, AZO spheres and rod-shaped nanoparticles with a similar morphology and particle size were obtained after performing the synthesis under identical conditions in the $500 \mathrm{~mL}$ reactor (see the ESI, $\uparrow$ Fig. S10).

To analyze the influence of the solvent on the crystal growth, in particular the effect of benzyl alcohol, solvent mixtures of benzylamine and benzyl alcohol were used to synthesize AZO nanoparticles. In the following, the nanocrystal size and morphology of the different samples are discussed based on the crystal sizes in the $l$ and $k$ dimensions as determined from the (010) and (002) reflections in the measured XRD patterns using the Scherrer equation. Therefore, the integral properties of the samples rather than the data from exemplary TEM images were taken into account. Fig. 3 shows the
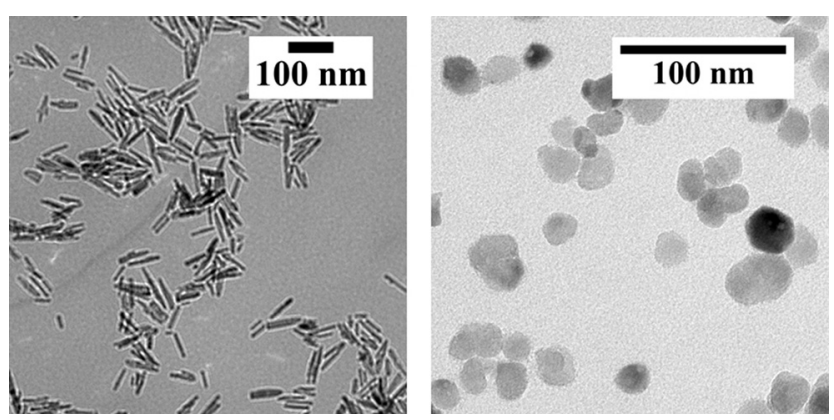

Fig. 2 TEM images of the rod-shaped AZO nanoparticles obtained in $\mathrm{BnOH}$ at a precursor concentration of $50.8 \mathrm{~g} \mathrm{~L}^{-1}$ (left) and the spherical AZO nanoparticles prepared in $\mathrm{BnNH}_{2}$ at a precursor concentration of $25.4 \mathrm{~g} \mathrm{~L}^{-1}$ (right). 
aspect ratio $l / k$ calculated from these sizes as a function of the used solvent composition for a standard precursor concentration of $50.8 \mathrm{~g} \mathrm{~L}^{-1}$. As the $h$ and $k$ directions are equivalent in the hexagonal lattice, the dimensions of the nanocrystals in these directions will be similar, which is confirmed by the TEM images. With an increase in the amount of the hydroxyl group-bearing species $\mathrm{BnOH}$ in the solvent mixture, higher aspect ratios, i.e. rod-shaped AZO nanocrystals, were obtained. Whereas lower volume fractions of the alcohol show a pronounced influence of the alcohol concentration on the aspect ratio, for a 50/50 vol\% mixture apparently saturation is reached and further increase in the alcohol concentration does not result in significant changes in the nanocrystal morphology. Hence, we infer that the particle morphology can be controlled via the content of hydroxyl groups in the reaction system, having a much stronger influence on crystal growth than the presence of amino groups. The XRD patterns and TEM images of these samples, confirming the morphology transition from $0 \mathrm{D}$ to $1 \mathrm{D}$, can be found in the ESI† section, Fig. S1 and S2.

The higher affinity of benzyl alcohol to the particle surface and thus the stronger influence on the particle growth were further investigated using thermogravimetric analysis (ESI, $\dagger$ Fig. S3). An increase in the volume content of benzyl alcohol in the solvent mixture leads to higher amounts of bound organics at the particle surface, which proves the higher affinity of $\mathrm{BnOH}$ to the particle surface as compared to $\mathrm{BnNH}_{2}$.

On the other hand, both aluminum acetylacetonate $\left(\mathrm{Al}(\mathrm{acac})_{3}\right)$ and aluminum isopropoxide $\left(\mathrm{Al}(\mathrm{OiPr})_{3}\right)$ were used as aluminum precursors. The calculated aspect ratios of nanocrystals obtained for the two precursors are shown in Fig. 4 for the different solvents and different precursor concentrations (for the corresponding XRD patterns see the ESI, $\dagger$ Fig. S4 and S5).

Again, it is clearly visible that the synthesis of AZO nanoparticles leads to the formation of AZO nanorods in $\mathrm{BnOH}$, with aspect ratios ranging between 2.5 and 3.6 depending on the precursor concentration, and spherical AZO nanocrystals in $\mathrm{BnNH}_{2}$, with aspect ratios around 1.0. The influence of the aluminum precursor is however minor. $\mathrm{Al}(\mathrm{acac})_{3}$ resulted in slightly higher aspect ratios for the synthesis in $\mathrm{BnOH}$ and

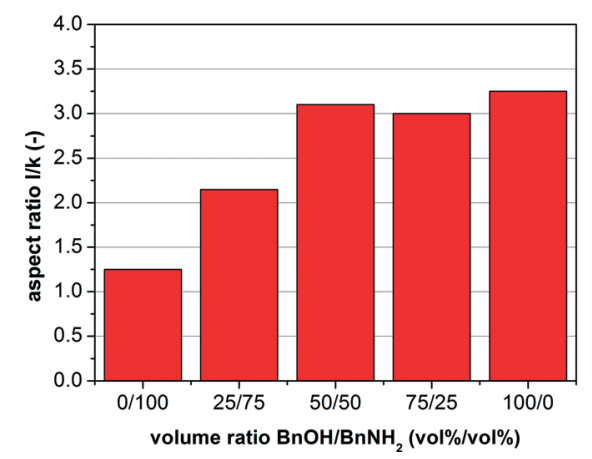

Fig. 3 Influence of the solvent on the morphology of the AZO nanocrystals.

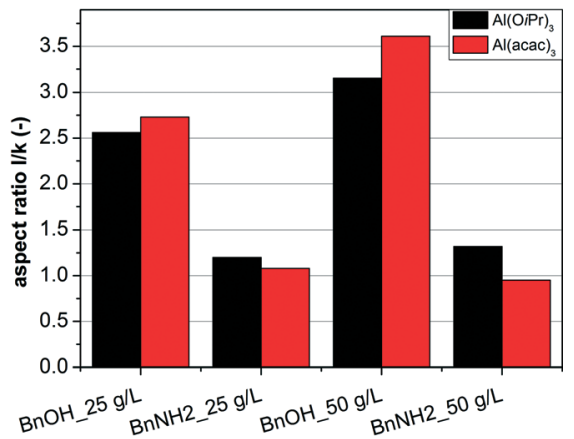

Fig. 4 Influence of the Al precursor on the morphology of the AZO nanocrystals.

smaller aspect ratios in $\mathrm{BnNH}_{2}$ as compared to the particles synthesized with $\mathrm{Al}(\mathrm{OiPr})_{3}$ as precursor. This effect may be attributed to the different side products of the precursors, as the formation of isopropanol for the synthesis using $\mathrm{Al}(\mathrm{OiPr})_{3}$ would lead to higher aspect ratios in $\mathrm{BnNH}_{2}$ due to the higher concentration of alcohols in the system, but might act as a competing agent in the $\mathrm{BnOH}$-based synthesis, limiting the effect of benzyl alcohol. Generally, the morphology of the forming AZO nanocrystals is mainly controlled by the chemistry of the used solvent rather than the chosen aluminum precursor. Due to these results and the toxicity of $\mathrm{Al}(\mathrm{acac})_{3}$, $\mathrm{Al}(\mathrm{OiPr})_{3}$ was used for all further investigations.

\subsection{Influence of the precursor concentration}

The precursor concentration was varied between 6.35 and $152.36 \mathrm{~g} \mathrm{~L} \mathrm{~L}^{-1}$, to investigate its influence on the size and shape of the AZO nanocrystals. To demonstrate the dependence of nanocrystal dimensions on the precursor concentration, the determined nanocrystal sizes are shown in the crystallographic $k$ and $l$ directions for the AZO nanocrystals prepared in $\mathrm{BnOH}$ at different precursor concentrations, however using a constant ratio of $2.5 \mathrm{~mol} \% \mathrm{Al}(\mathrm{OiPr})_{3}$ (Fig. $5 a)$. Due to the preferred growth direction, an increase in the precursor concentration leads to consequent further growth in the $l$ direction. Notably, the particle size in the $k$ direction is constant for all precursor concentrations. This clearly indicates that crystal growth is blocked in the $k$ direction and the presence of higher amounts of precursor results in larger elongation of the nanorods.

On the other hand, the concentration dependence of the crystallite size in the two crystallographic directions is strongly different for the spherical AZO nanoparticles (Fig. 5b). For higher concentrations, stronger crystal growth is observed in both directions. As a result of the higher surface energy of the (001) crystal faces, growth of the AZO nanoparticles in the $l$ direction is slightly enhanced, which becomes more pronounced with increasing availability of monomer species. However, in comparison to the formation of AZO nanocrystals in the $\mathrm{BnOH}$ system, the use of $\mathrm{BnNH}_{2}$ as a solvent does not lead to strongly preferred growth in the 
a)

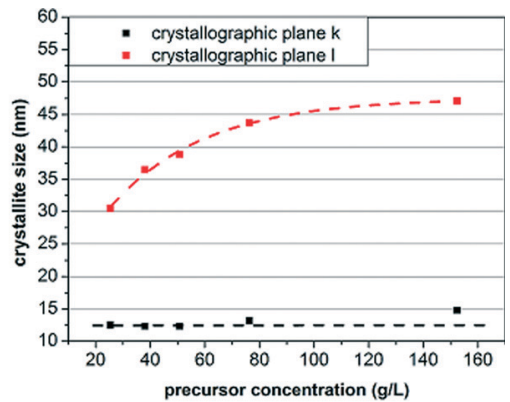

b)

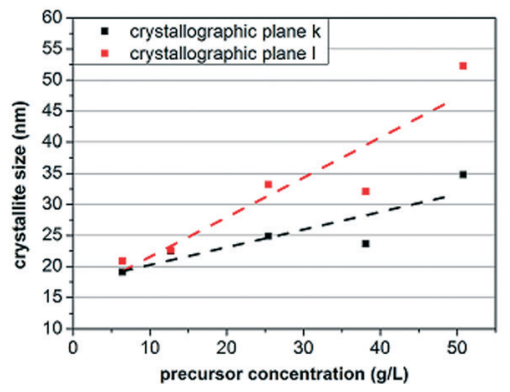

Fig. 5 Crystallite size as a function of the precursor concentration of a) the AZO nanorods synthesized in benzyl alcohol and b) the AZO nanocrystals prepared in benzylamine.

$l$ direction; hence nanocrystals with an aspect ratio of around 1 can be formed. Moreover, the nanocrystal size can be adjusted by the precursor concentration (for the corresponding XRD patterns see the ESI, $\dagger$ Fig. S6 and S7).

\subsection{Influence of the Al doping}

As an alternative to indium tin oxide as TCO for different applications, AZO nanoparticles with controllable doping concentrations are desired in order to tailor the electronic properties. To investigate the incorporation of Al into the crystal lattice as well as the influence of the aluminum doping on the resulting morphology, the concentration of added $\mathrm{Al}(\mathrm{OiPr})_{3}$ was varied between 1 and $30 \mathrm{~mol} \%$. Firstly, using ICP-OES analysis, the expected linear increase in the aluminum content of the nanocrystals was confirmed for both solvents (Fig. 6). Whilst the doping level can nicely be tuned by the amount of precursor, the $\mathrm{Al}$ contents of the samples are significantly lower than the initial content in the system.

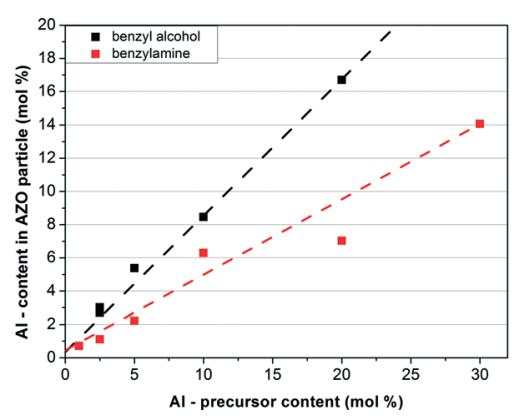

Fig. 6 Al content of the AZO nanoparticles measured by ICP-OES as a function of the content of added aluminum precursor.
Notably, whilst previously saturation of the doping level at about $10 \mathrm{~mol} \%$ was reported for microwave-based synthesis ${ }^{13}$ under the conditions applied, here significantly higher doping levels could be achieved especially in $\mathrm{BnOH}$. On the other hand, the aluminum doping level had no significant effect on the resulting morphologies for both systems ( $c f$. the ESI, $\dagger$ Fig. S8).

Furthermore, the optical properties of the resulting nanocrystals were determined using UV-Vis measurements. Fig. 7 displays the spectra of spherical AZO nanocrystals (with an actual content of 1 and $2.5 \mathrm{~mol} \% \mathrm{Al}$ ) compared to the undoped spherical $\mathrm{ZnO}$ particles prepared in $\mathrm{BnNH}_{2}$. All $\mathrm{AZO}$ particles were measured as stable dispersion in ethanol, having primary particle sizes of about $40 \mathrm{~nm}$. A blueshift of the absorption for the Al-doped nanocrystals can clearly be observed in comparison to the undoped spherical particles.

The bandgap of a crystalline semiconductor can be calculated via the Kubelka-Munk equation for direct allowed transitions:

$$
(h v \times \alpha)^{2}=A\left(h v-E_{\mathrm{g}}\right)
$$

where $h$ is Planck's constant, $v$ the frequency of the excitation wavelength, $\alpha$ the absorption coefficient, $A$ a proportionality factor and $E_{\mathrm{g}}$ the bandgap.

To derive the optical bandgap of the measured nanocrystals, the Tauc plot based on eqn (1) was applied to the measured UV-Vis spectra (Fig. 8). The extrapolation of the linear part of the curve can be used to determine the value of the excitation energy from the intersection with the abscissa. For the undoped $\mathrm{ZnO}$ nanocrystals prepared in $\mathrm{BnNH}_{2}$, an optical bandgap of $3.07 \mathrm{eV}$ was calculated. For the spherical AZO nanocrystals, an increase in the bandgap energy was found, reaching about $3.24 \mathrm{eV}$ for a doping level of $2.5 \mathrm{~mol} \%$ (see the ESI, $\dagger$ Fig. S9, for the bandgap energies for different doping levels). In contrast, the rod-shaped $\mathrm{ZnO}$ nanocrystals showed a bandgap of about $3.3 \mathrm{eV}$ as expected (the usual literature values range between 3.15 and $3.4 \mathrm{eV}),{ }^{24-26}$ and did not change significantly for increased Al doping levels. The comparably low bandgap of the synthesized spherical nanocrystals is attributed to their high crystallinity and larger size

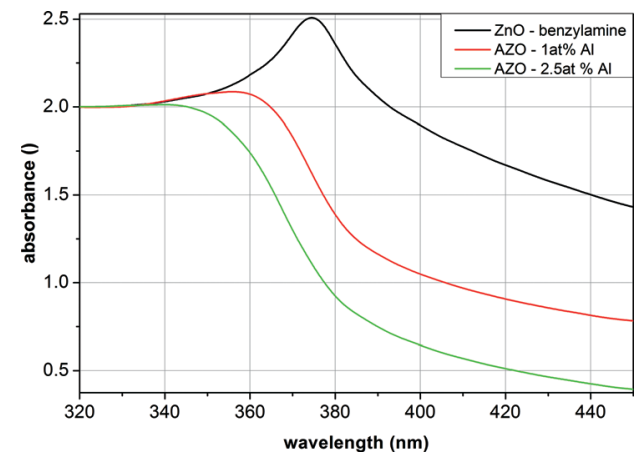

Fig. 7 UV-Vis measurements of $\mathrm{ZnO}$ as well as the AZO nanoparticles synthesized in benzylamine with different Al contents. 


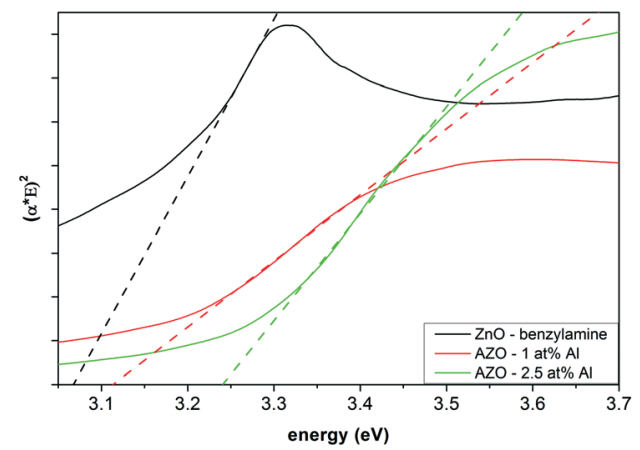

Fig. 8 Tauc plot of the AZO nanocrystals with different doping concentrations as compared to the undoped $\mathrm{ZnO}$ nanoparticles (all samples prepared in benzylamine).

(about $40 \mathrm{~nm}$ in all the directions) as compared to the rodshaped AZO nanocrystals (having a diameter of only $12.5 \mathrm{~nm}$ and, only in the $l$ direction, a length of $40 \mathrm{~nm}$ ). In comparison to the products of other studies, also the influence of the organics might play a role. ${ }^{13,26}$ The increase in bandgap energy with the $\mathrm{Al}$ concentration has been reported in a similar fashion before. ${ }^{13,26-28}$ For higher doping levels, a plateau at about $3.25 \mathrm{eV}$ for the spherical nanocrystals, and at about $3.32 \mathrm{eV}$ for the nanorods was found (see the ESI, $\dagger$ Fig. S9). This performance is well-known for n-type semiconductors and can be explained by the Burstein-Moss effect. With successful doping of $\mathrm{ZnO}$ with $\mathrm{Al}^{3+}$ ions, the $\mathrm{Zn}^{2+}$ ions in the lattice are substituted and one additional electron is located in the conduction band. If an electron occupies the lowest state in the conduction band, an excited electron from the valence band needs more energy to reach a higher state, because the Pauli principle prohibits it from occupying the same state. ${ }^{22,23}$

\subsection{Influence of the reaction time and temperature}

To investigate the growth kinetics of the AZO nanocrystals, experiments under variation of the reaction time from 30 min to $72 \mathrm{~h}$ were performed for the synthesis in $\mathrm{BnOH}$ and $\mathrm{BnNH}_{2}$ at $200{ }^{\circ} \mathrm{C}$ with a precursor concentration of $50.8 \mathrm{~g} \mathrm{~L}^{-1}$ (2.5 $\left.\mathrm{mol} \% \mathrm{Al}(\mathrm{OiPr})_{3}\right)$. The calculated crystallite sizes for the obtained samples are presented in Fig. 9a, for the $\mathrm{BnOH}$ system, and in Fig. 9b, for the $\mathrm{BnNH}_{2}$ system.

Surprisingly, in the $\mathrm{BnOH}$ synthesis, nanorods with an aspect ratio of around 3.2 are already formed after a short reaction time of $30 \mathrm{~min}$, showing a size of approximately 12 $\mathrm{nm}$ in the crystallographic plane $k$ and $40 \mathrm{~nm}$ in the crystallographic plane $l$. No significant further growth is observed for longer reaction times, pointing to a fast formation process in the alcohol. In contrast, growth of the AZO nanocrystals in $\mathrm{BnNH}_{2}$ is much slower, with an exponential increase in the crystal size in both directions being determined within the first $12 \mathrm{~h}$. Notably, the nanocrystals are elongated initially with an aspect ratio of about 2.0 but become rather spherical in the course of the reaction over the following hours. This ripening process is also expressed by a slight decrease in size in the crystallographic $l$ direction for long reaction times, a)

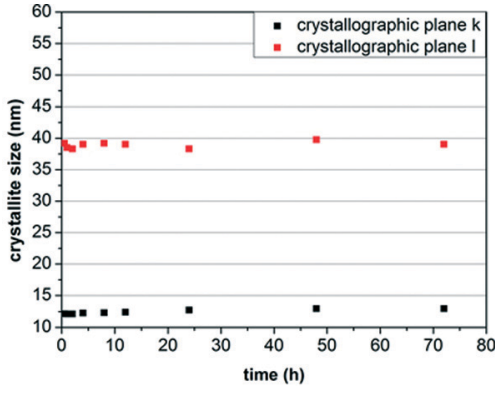

b)

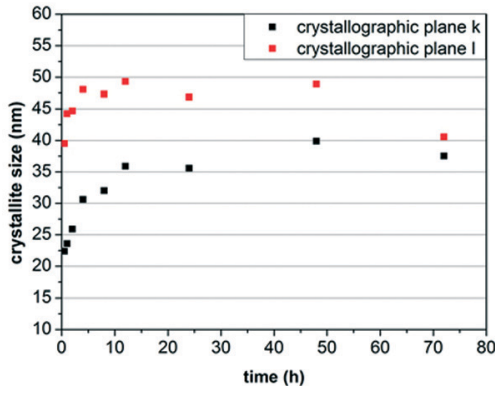

Fig. 9 Influence of the reaction time on the crystallite size of the AZO nanocrystals synthesized in benzyl alcohol (a) and benzylamine (b).

pointing to a stabilization of the spherical crystal morphology in $\mathrm{BnNH}_{2}$. This different particle growth can be attributed to the different binding affinities of $\mathrm{BnOH}$ and $\mathrm{BnNH}_{2}$ to the nanocrystals as discussed above. We furthermore propose that $\mathrm{BnOH}$ strongly coordinates with all crystal faces, preventing any growth and resulting in 1D nanocrystals that already form after initial crystallization. In contrast, $\mathrm{BnNH}_{2}$ shows weaker binding but stabilizes the (001) crystal faces, resulting in the formation of $0 \mathrm{D}$ nanocrystals after ripening. The tendency of amines to favor the growth in the $h$ and $k$ directions over the $l$ direction at high concentrations is wellknown for the synthesis of $\mathrm{ZnO}$ in alkylamines. ${ }^{29}$

Moreover, the influence of the reaction temperature was investigated between 80 and $200{ }^{\circ} \mathrm{C}$. Here, a precursor concentration of $50.8 \mathrm{~g} \mathrm{~L}^{-1}\left(2.5 \mathrm{~mol} \% \mathrm{Al}(\mathrm{OiPr})_{3}\right)$ was used with a reaction time of $24 \mathrm{~h}$. As clearly visible in Fig. 10, no significant influence of the reaction temperature on the resulting aspect ratio of $\mathrm{AZO}$ nanorods in $\mathrm{BnOH}$ was determined. For the synthesis of AZO nanocrystals in $\mathrm{BnNH}_{2}$, however, a

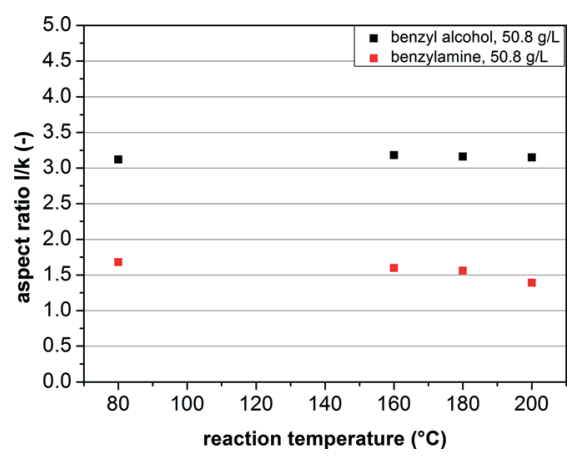

Fig. 10 Influence of the reaction temperature on the aspect ratio of the $\mathrm{AZO}$ nanocrystals prepared in $\mathrm{BnOH}$ and $\mathrm{BnNH}_{2}$. 
decrease in the aspect ratio with higher reaction temperatures from 1.7 down to 1.2 was identified. Thus, to form spherical particles, a reaction temperature of $200{ }^{\circ} \mathrm{C}$ is necessary, which again indicates a ripening effect, which is clearly enhanced at higher temperatures, as responsible for the formation of spherical nanocrystals.

\section{Conclusions}

In this study, we presented an easy and controllable approach to synthesize AZO nanocrystals with customized size and morphology. The morphology of the synthesized nanostructures strongly depends on the reaction chemistry, which is crucially influenced by the used solvent. Spherical nanoparticles were formed in benzylamine, whereas in benzyl alcohol as well as mixtures with high volume contents of the alcohol, AZO nanorods are obtained. Detailed studies revealed that this can be attributed to the different binding affinities of the solvents to the nanocrystals, with $\mathrm{BnOH}$ showing strong binding, preventing any further growth or ripening, whereas $\mathrm{BnNH}_{2}$ shows less strong binding to the surface, and ripening effects lead to spherical nanoparticles after long reaction times. Furthermore, our approach allowed the preparation of highly crystalline particles at low reaction temperatures between 80 and $200{ }^{\circ} \mathrm{C}$ at different scales up to $500 \mathrm{~mL}$. The level of doped aluminum could be varied by adjusting the $\mathrm{Al}$ precursor concentration, allowing the synthesis of nanocrystals with not only tailored size and morphology but also tuned optical properties and bandgap energy.

\section{Acknowledgements}

The authors gratefully acknowledge P. Schmidt, Institute of Geoecology, TU Braunschweig, for ICP-OES measurements. Furthermore, we thank Dr. I.-C. Masthoff, Institute for Particle Technology, TU Braunschweig, as well as Axel Freytag and Dr. N. C. Bigall, Institute of Physical Chemistry and Electrochemistry and Laboratory of Nano and Quantum Engineering, Leibniz University Hannover, for the TEM images.

\section{Notes and references}

1 S. Hartner, A. Moazzam, C. Schulz, M. Winterer and H. Wiggers, Nanotechnology, 2009, 20, 1-8.

2 R. G. Gordon, MRS Bull., 2000, 25, 52-57.

3 E. Fortunato, D. Ginley, H. Hosono and D. C. Paine, MRS Bull., 2007, 32, 242-247.

4 V. Bhosle, A. Tiwari and J. Narayan, Appl. Phys. Lett., 2006, 88, 032106.

5 N. Neves, R. Barros, E. Antunes, J. Calado, E. Fortunato, R. Martins and I. Ferreira, J. Eur. Ceram. Soc., 2012, 32, 4381-4391.
6 J. B. Shim, H. S. Kim, H. Chang and S.-O. Kim, J. Mater. Sci.: Mater. Electron., 2011, 22, 1350-1356.

7 Z. Lu, J. Zhou, A. Wang, N. Wang and X. Yang, J. Mater. Chem., 2011, 21, 4161-4167.

8 N. G. Dhere, Sol. Energy Mater. Sol. Cells, 2006, 90, 2181-2190.

9 X. Jiang, F. L. Wong, M. K. Fung and S. T. Lee, Appl. Phys. Lett., 2003, 83, 1875-1877.

10 T. Minami, Semicond. Sci. Technol., 2005, 20, S35-S44.

11 Y. Furubayashi, T. Hitosugi, Y. Yamamoto, K. Inaba, G. Kinodo, Y. Hirose, T. Shimada and T. Hasegawa, Appl. Phys. Lett., 2005, 86, 252101.

12 T. Strachowski, E. Grzanka, W. Lojkowski, A. Presz, M. Godlewski, S. Yatsunenko, H. Matysiak, R. R. Piticescu and C. J. Monty, J. Appl. Phys., 2007, 102, 073513.

13 L. Luo, M. D. Rossell, D. Xie, R. Erni and M. Niederberger, ACS Sustainable Chem. Eng., 2013, 1, 152-160.

14 R. Buonsanti, A. Llordes, S. Aloni, B. A. Helms and D. L. Milliron, Nano Lett., 2011, 11, 4706-4710.

15 R. R. Mohan, K. Sambath and K. Rajendran, J. Mater. Sci.: Mater. Electron., 2015, 26, 1748-1755, DOI: 10.1007/s10854014-2603-x.

16 Z. Chen, G. Zhan, Y. Wu, X. He and Z. Lu, J. Alloys Compd., 2014, 587, 692-697.

17 G. Garnweitner and M. Niederberger, J. Mater. Chem., 2008, 18, 1171-1182.

18 M. Niederberger and G. Garnweitner, Chem. - Eur. J., 2006, 12, 7282-7302.

19 G. Garnweitner, N. Tsedev, H. Dierke and M. Niederberger, Eur. J. Inorg. Chem., 2008, 890-895.

20 E. Hammarberg, A. Prodi-Schwab and C. Feldmann, J. Colloid Interface Sci., 2009, 334, 29-36.

21 I. Bilecka and M. Niederberger, Electrochim. Acta, 2010, 55, 7717-7725.

22 B. Ludi and M. Niederberger, Dalton Trans., 2013, 42, 12554-12568.

23 S. C. Abrahams and J. L. Bernstein, Acta Crystallogr., Sect. B: Struct. Crystallogr. Cryst. Chem., 1969, 25, 1233-1236.

24 Ü. Özgür, Y. I. Alivov, C. Liu, A. Teke, M. A. Reshchikov, S. Dogan, V. Avrutin, S.-J. Cho and H. Morkoç, J. Appl. Phys., 2005, 98, 041301.

25 B. Wen, Y. Huang and J. J. Boland, J. Phys. Chem. C, 2008, 112, 106-111.

26 S. Suwanboon, P. Amornpitoksuk, A. Haidoux and J. C. Tedenac, J. Alloys Compd., 2008, 462, 335-339.

27 Y. Zhang, Y. Yang, J. Zhao, R. Tan, W. Wang, P. Cui and W. Song, J. Mater. Sci., 2011, 46, 774-780.

28 H. Zhou, H. Wang, K. Zheng, Z. Gu, Z. Wu and X. Tian, RSC Adv., 2014, 4, 42758-42763.

29 Z. Zhang, M. Lu, H. Xu and W.-S. Chin, Chem. - Eur. J., 2007, 13, 632-638. 